\title{
Platelet Function Measured Using a Whole Blood Aggregometer Can Predict Bleeding Events
}

\author{
Akinori Sairaku ${ }^{1}$, Yukiko Nakano ${ }^{2}$, Shin Eno ${ }^{1}$, Tatsuya Hondo ${ }^{1}$, Keiji Matsuda ${ }^{1}$, Tomohiko Kisaka $^{1}$, and \\ Yasuki Kihara $^{2}$ \\ ${ }^{1}$ Department of Cardiology, Chugoku Workers Compensation Hospital, Kure, Japan \\ ${ }^{2}$ Department of Cardiology, Hiroshima University, Hiroshima, Japan
}

\begin{abstract}
Aim: We hypothesized that excessive suppression of platelet function due to antiplatelet therapy can increase the incidence of bleeding complications. The aim of the present study was to find whether we could predict bleeding events by measuring platelet function.

Methods: We enrolled 743 subjects whose platelet function was measured using a whole blood aggregometer based on a screen filtration pressure method. Of these subjects, $551(74.2 \%)$ were treated with some type of antiplatelet agent. The endpoints were bleeding or ischemic events requiring hospitalization or extension of hospital stay. We prospectively compared the platelet function of subjects with and without bleeding or ischemic events.

Results: During $556 \pm 207$ days of follow-up, 52 (7.0\%) bleeding events and 20 (2.7\%) ischemic events were observed. Kaplan-Meier analysis using the log-rank test revealed that an aggregation rate of $<20 \%$ induced by $8 \mu \mathrm{M}$ adenosine diphosphate (ADP) was significantly associated with a greater number of bleeding events $(11.9 \%$ vs. $5.2 \% ; p=0.0007)$. Cox proportional hazards model showed that age $>75$ years (hazard ratio $[\mathrm{HR}], 1.78 ; 95 \%$ confidence interval $[\mathrm{CI}], 1.03-3.10 ; p=0.039$ ), estimated glomerular filtration rate $<60 \mathrm{~mL} / \mathrm{min} / 1.73 \mathrm{~m}^{2}(\mathrm{HR}, 1.82 ; 95 \% \mathrm{CI}, 1.06-3.18 ; p=0.031)$ and aggregation rate $<20 \%$ induced by $8 \mu \mathrm{M}$ ADP (HR, 2.18; 95\% CI, 1.24-3.80; $p=0.0071$ ) were independent predictors of bleeding events.

Conclusions: Low platelet function demonstrated using a whole blood aggregometer was an independent predictor of bleeding complications.
\end{abstract}

J Atheroscler Thromb, 2011; 18:16-23.

Key words; Platelet function assay, Screen filtration pressure method, Aggregation rate, Antiplatelet agents, Bleeding event

\section{Introduction}

Aspirin has been considered essential for the secondary prevention of atherosclerotic disease ${ }^{1)}$, and dual antiplatelet therapy with aspirin and thienopyridine or clopidogrel is the cornerstone for the management of patients undergoing percutaneous coronary intervention; however, antiplatelet therapy occasional-

Address for correspondence: Akinori Sairaku, Department of Cardiology, Hiroshima University, 1-2-3 Kasumi, Minami-ku, Hiroshima 734-8551, Japan

E-mail: rjrgw059@ybb.ne.jp

Received: April 20, 2010

Accepted for publication: August 17, 2010 ly induces bleeding complications. Since Asian populations have a relatively high incidence of bleeding compared with other ethnic groups ${ }^{2-5}$, it is prudent to carefully monitor Japanese patients treated with antiplatelet agents to prevent severe bleeding.

Recently, it was reported that residual platelet reactivity or resistance to antiplatelet agents, as measured with a platelet function assay, is strongly associated with ischemic events ${ }^{6-10)}$, and the efficacy of the platelet function assay for patients treated with antiplatelet agents has been validated; however, these studies did not focus on bleeding events but rather focused on ischemic events, including coronary artery stent thrombosis. Furthermore, there have been few studies 
on the association between the results of ex vivo platelet function tests and the frequency of bleeding events. We therefore examined whether we could predict bleeding events in patients treated with antiplatelet agents using data derived from platelet function assays.

\section{Methods}

\section{Study Population and Clinical Endpoints}

This was a single-center, prospective observational study. Subjects were eligible for inclusion in the present study if their platelet aggregation function had been measured at Chugoku Workers Compensation Hospital. Subjects were excluded if they had been previously diagnosed with serious hematological disease, significant anemia with a hemoglobin level $<10 \mathrm{~g} / \mathrm{dL}$, severe liver damage (Child-Pugh class B or C), and severely impaired renal function, defined as the estimated glomerular filtration rate $(\mathrm{eGFR})^{11)}<30 \mathrm{ml} / \mathrm{min} /$ $1.73 \mathrm{~m}^{2}$. Additional exclusion criteria were uncontrolled hypertension and regular use of nonsteroidal antiinflammatory drugs or selective serotonin reuptake inhibitors. After enrollment, subjects were scheduled to be followed up for 18 months to ascertain the occurrence of clinical events. Follow-up was by medical visits or telephone calls.

The primary endpoint was a bleeding event requiring hospitalization or extension of hospital stay. The secondary endpoint was an ischemic event defined as an ischemic stroke, myocardial infarction (including coronary artery stent thrombosis), or peripheral artery occlusion. Patients were censored at clinical endpoints, loss to follow-up, discontinuation of prescribed antiplatelet or anticoagulant agents, and death.

Written informed consent was obtained from all patients, and the study protocol was approved by the research committee of our institution.

\section{Platelet Function Measurement}

Platelet function was measured using a whole blood aggregometer based on a screen filtration pressure method (WBA analyzer; LMS Co., Ltd., Tokyo, Japan). Study procedures were conducted according to the method described by Ozeki et al. ${ }^{12)}$ and Sudo et al. ${ }^{13)}$. Briefly, whole blood aggregation was induced by adding $8 \mu \mathrm{M}$ adenosine diphosphate (ADP) to $200 \mu \mathrm{L}$ whole blood. Five minutes later, the absorbing pressure of the aggregated whole blood was measured through the screen of a microsieve $\left(300 \mu \mathrm{m}^{2}\right.$ pore size). The results are expressed as aggregation rates. A negative pressure of $-130 \mathrm{~mm} \mathrm{Hg}$ was defined as $100 \%$ and $-6 \mathrm{~mm} \mathrm{Hg}$ as $0 \%$.

International normalized ratio (INR) values were also measured in subjects who were prescribed warfarin. The average aggregation rates and the INR values obtained on three different days were analyzed for each subject. All measurements were performed at least a week after the start of newly prescribed antiplatelet or anticoagulant agents for the enrolled subjects, except for the control subjects. (subjects not taking antiplatelet or anticoagulant agents)

\section{Statistical Analysis}

Continuous variables are presented as the mean $\pm \mathrm{SD}$ and categorical variables as frequency (percentage). Continuous variables were assessed using Student's $t$-test, and categorical variables were compared using chi-square statistics. Aggregation rates induced by $8 \mu \mathrm{M}$ ADP were divided into quartiles $(<20 \%$, $20 \%$ to $<40 \%, 40 \%$ to $<80 \%, \geq 80 \%$ ) to compare the frequency of bleeding events across quartiles, and were dichotomized according to the mean aggregation rate induced by $8 \mu \mathrm{M}$ ADP to determine whether there was a difference in the frequency of ischemic events between subjects with values below and above the mean aggregation rate. Kaplan-Meier analysis was used to assess the time taken for bleeding or ischemic events to occur. The log-rank test was used to compare the bleeding event-free survival between subjects within the first (lowest) quartile of aggregation rates induced by $8 \mu \mathrm{M}$ ADP and the remaining subjects, and to compare ischemic event-free survival between subjects with an aggregation rate below and above the mean aggregation rate induced by $8 \mu \mathrm{M}$ ADP. Univariate and multivariate Cox proportional hazards analyses were performed using clinical factors related to bleeding to determine predictors of a bleeding event. Variables with a $p$ value of $<0.1$ in univariate analysis were included in multivariate models. A $p$ value of $<0.05$ was considered significant. All analyses were performed using JMP software version 5.1 (SAS Institute Japan Co., Ltd., Tokyo, Japan).

\section{Results}

\section{Patient Characteristics and Medications Used}

We enrolled 743 subjects (mean age, $72 \pm 11$ years; 470 men and 273 women) between January 2007 and January 2008. The baseline characteristics of the entire group of study subjects are presented in Table 1. A little over half of all the subjects had ischemic heart disease and we found atrial fibrillation in slightly more than $10 \%$ of all the subjects. The mean platelet aggregation rate induced by $8 \mu \mathrm{M}$ ADP was $47.3 \pm 33.7 \%$ (Table 1). A total of 117 (15.7\%) subjects were treated with one type of antiplatelet agent 
Table 1. Baseline characteristics of study subjects

\begin{tabular}{lc}
\hline$N$ & 743 \\
Male & $470(63 \%)$ \\
Age (years) & $72 \pm 11$ \\
Underlying disease & \\
$\quad$ Hypertension & $401(54 \%)$ \\
$\quad$ Diabetes mellitus & $253(34 \%)$ \\
$\quad$ Ischemic heart disease & $417(56 \%)$ \\
$\quad$ Coronary artery bypass grafting & $110(15 \%)$ \\
$\quad$ Atrial fibrillation & $89(12 \%)$ \\
$\quad$ Previous stroke & $49(7 \%)$ \\
$\quad$ Arteriosclerosis obliterans & $47(6 \%)$ \\
$\quad$ Previous valve replacement & $46(6 \%)$ \\
$\quad$ Congestive heart failure & $80(11 \%)$ \\
Body mass index $\left(\mathrm{kg} / \mathrm{m}^{2}\right)$ & $23.8 \pm 4.3$ \\
Estimated glomerular filtration rate $\left(\mathrm{ml} / \mathrm{min} / 1.73 \mathrm{~m}^{2}\right)$ & $65.2 \pm 19.4$ \\
Hemoglobin level $(\mathrm{g} / \mathrm{dL})$ & $12.8 \pm 1.6$ \\
Platelet count $\left(\times 10^{4} / \mu \mathrm{L}\right)$ & $16.9 \pm 5.4$ \\
Platelet aggregation rate induced by $8 \mu \mathrm{M} \mathrm{ADP}(\%)$ & $47.3 \pm 33.7$ \\
Medication & \\
$\quad$ Antiplatelet agents & $551(74 \%)$ \\
Warfarin & $241(32 \%)$ \\
Proton pump inhibitor/H2 blocker & $375(50 \%)$ \\
\hline
\end{tabular}

alone, $246(33.1 \%)$ with two or three types of antiplatelet agents, $53(7.1 \%)$ with warfarin alone, 188 $(25.3 \%)$ with a combination of antiplatelet agents and warfarin, and $139(18.7 \%)$ with no antiplatelet or anticoagulation agents. Proton pump inhibitors or $\mathrm{H} 2$ blockers were prescribed in half of all the subjects (Table 1 ).

The types of antiplatelet agents prescribed and their usual daily doses were as follows: $81 \mathrm{mg}$ aspirin, $200 \mathrm{mg}$ ticlopidine, $75 \mathrm{mg}$ clopidogrel, $100 \mathrm{mg}$ cilostazol, and $120 \mu \mathrm{g}$ prostaglandin. For subjects who received anticoagulant therapy, the dose of warfarin was based on INR.

\section{Differences in Clinical Endpoints and Platelet Aggregation Rate Depending on Medications}

The mean follow-up period was 556 \pm 207 days. During this period, $52(7.0 \%)$ bleeding events occurred; 25 (48.0\%) gastrointestinal bleeds, 10 (19.2\%) intracranial hemorrhages, 8 (15.4\%) access site-related bleeds after percutaneous coronary intervention, and $9(17.3 \%)$ bleeds due to other causes. We observed 20 $(2.7 \%)$ ischemic events; $11(55.0 \%)$ cerebral infarctions, $5(25.0 \%)$ coronary artery stent thromboses, and $4(20.0 \%)$ peripheral artery occlusions (Table 2 ).

The frequency of bleeding and ischemic events, the platelet aggregation rate induced by $8 \mu \mathrm{M}$ ADP, and INR for each medication combination are shown
Table 2. Bleeding and ischemic events

\begin{tabular}{lc}
\hline Events & $n$ \\
Bleeding events & 52 \\
Gastrointestinal bleeding & $25(48.0 \%)$ \\
Intracranial hemorrhage & $10(19.2 \%)$ \\
Access site-related bleeding during PCI & $8(15.4 \%)$ \\
Hemothorax & $2(3.8 \%)$ \\
Traumatic hemorrhage & $2(3.8 \%)$ \\
Severe hematuria & $2(3.8 \%)$ \\
Renal hemorrhage & $2(1.9 \%)$ \\
Intraperitoneal bleeding & $2(1.9 \%)$ \\
Bleeding from prostate & $2(1.9 \%)$ \\
Ischemic events & 20 \\
Ischemic stroke & $11(55.0 \%)$ \\
Coronary artery stent thrombosis & $5(25.0 \%)$ \\
Peripheral artery occlusion & $4(20.0 \%)$ \\
\hline
\end{tabular}

PCI, percutaneous coronary intervention

in Table 3. Subjects who took a combination of aspirin and warfarin and those who took other medication combinations (including various combinations of aspirin, cilostazol, clopidogrel, ticlopidine, prostaglandin, and warfarin) had a significantly greater number of bleeding events than those who took no antiplatelet or anticoagulant agents; however, there was no difference in the number of ischemic events between subjects taking and not taking any antiplatelet or anticoagulant agents. The aggregation rate was significantly lower in subjects taking antiplatelet agents than in those not taking these agents. However, the aggregation rate was similar in subjects taking cilostazol or warfarin and in those not taking any medication. INR was significantly lower in subjects taking a combination of aspirin, ticlopidine, and warfarin than in those taking warfarin alone.

\section{Frequency of Bleeding or Ischemic Events According to Aggregation Rate Induced by $8 \mu \mathrm{M}$ ADP and Kaplan-Meier Analysis}

Significant differences in the frequency of bleeding events were observed between the first quartile of the aggregation rate induced by $8 \mu \mathrm{M}$ ADP $(<20 \%)$ and the third quartile ( $40 \%$ to $<80 \%)(11.9 \%$ vs. $5.6 \%, p=0.033$ ) or fourth quartile ( $\geq 80 \%)$ (vs. $3.2 \%$, $p=0.0014)$ (Fig. 1). The ischemic event rate was significantly higher in subjects with an aggregation rate $\geq 47 \%$ induced by $8 \mu \mathrm{M}$ ADP compared with those with an aggregation rate $<47 \%$ ( $4.1 \%$ vs. $1.6 \%, p=$ 0.038) (Fig. 2).

Kaplan-Meier analysis using the log-rank test revealed that aggregation rates of $<20 \%$ were significantly associated with a greater number of bleeding 
Table 3. Frequency of bleeding and ischemic events, platelet aggregation rate induced by $8 \mu \mathrm{M}$ ADP, and INR for each combination of medications

\begin{tabular}{|c|c|c|c|c|c|c|c|c|c|}
\hline Medications & $n$ & $\begin{array}{l}\text { Bleeding } \\
\text { events }\end{array}$ & $p$ value* & $\begin{array}{c}\text { Ischemic } \\
\text { events }\end{array}$ & $p$ value** & $\begin{array}{l}\text { Aggregation } \\
\text { rate }(\%)\end{array}$ & $p$ value $* * *$ & INR & $p$ value $^{\S}$ \\
\hline Aspirin and ticlopidine & 208 & $12(6 \%)$ & 0.55 & $7(3 \%)$ & 0.27 & $28.9 \pm 23.0$ & $<0.001$ & - & - \\
\hline Ticlopidine and warfarin & 63 & $5(8 \%)$ & 0.29 & $1(2 \%)$ & 0.94 & $39.0 \pm 31.1$ & $<0.001$ & $1.7 \pm 0.5$ & 0.55 \\
\hline Aspirin & 61 & $3(5 \%)$ & 0.85 & $1(2 \%)$ & 0.91 & $48.5 \pm 34.0$ & $<0.001$ & - & - \\
\hline Aspirin, ticlopidine, and warfarin & 54 & $6(11 \%)$ & 0.08 & $1(2 \%)$ & 0.84 & $27.1 \pm 21.0$ & $<0.001$ & $1.4 \pm 0.4$ & 0.002 \\
\hline Warfarin & 53 & $3(6 \%)$ & 0.69 & $3(6 \%)$ & 0.1 & $76.2 \pm 27.8$ & 0.58 & $1.7 \pm 0.7$ & - \\
\hline Aspirin and warfarin & 36 & $6(17 \%)$ & 0.009 & $1(3 \%)$ & 0.6 & $51.6 \pm 30.0$ & $<0.001$ & $1.5 \pm 0.3$ & 0.1 \\
\hline Ticlopidine & 28 & $1(4 \%)$ & 0.86 & $0(0 \%)$ & 0.52 & $39.7 \pm 24.8$ & $<0.001$ & - & - \\
\hline Aspirin and clopidogrel & 20 & $2(10 \%)$ & 0.27 & $1(5 \%)$ & 0.28 & $23.2 \pm 13.3$ & $<0.001$ & - & - \\
\hline Cilostazol & 12 & $0(0 \%)$ & 0.46 & $0(0 \%)$ & 0.68 & $60.2 \pm 34.8$ & 0.95 & - & - \\
\hline Cilostazol and warfarin & 12 & $1(8 \%)$ & 0.4 & $1(8 \%)$ & 0.1 & $65.2 \pm 42.0$ & 0.86 & $1.9 \pm 0.8$ & 0.38 \\
\hline Other combinations ${ }^{\dagger}$ & 57 & $7(12 \%)$ & 0.04 & $2(4 \%)$ & 0.35 & $23.2 \pm 13.6$ & $<0.001$ & - & - \\
\hline None & 139 & $6(4 \%)$ & - & $2(1 \%)$ & - & $75.2 \pm 30.2$ & - & - & - \\
\hline Total & 743 & $52(7 \%)$ & - & $20(3 \%)$ & - & $47.3 \pm 33.7$ & - & - & - \\
\hline
\end{tabular}

Aggregation rate, aggregation rate induced by $8 \mu \mathrm{M}$ ADP

* All differences between the frequency of bleeding events with each medication and without any medication.

**All differences between the frequency of ischemic events with each medication and without any medication.

*** All differences between the aggregation rates induced by $8 \mu \mathrm{M}$ ADP with each medication and without any medication.

${ }_{1}^{\S}$ All differences between the INR values with each combination of antiplatelet agents and warfarin, and with warfarin alone.

'Other combinations include various combinations of medications chosen from aspirin, cilostazol, clopidogrel, ticlopidine, prostaglandin, and warfarin.

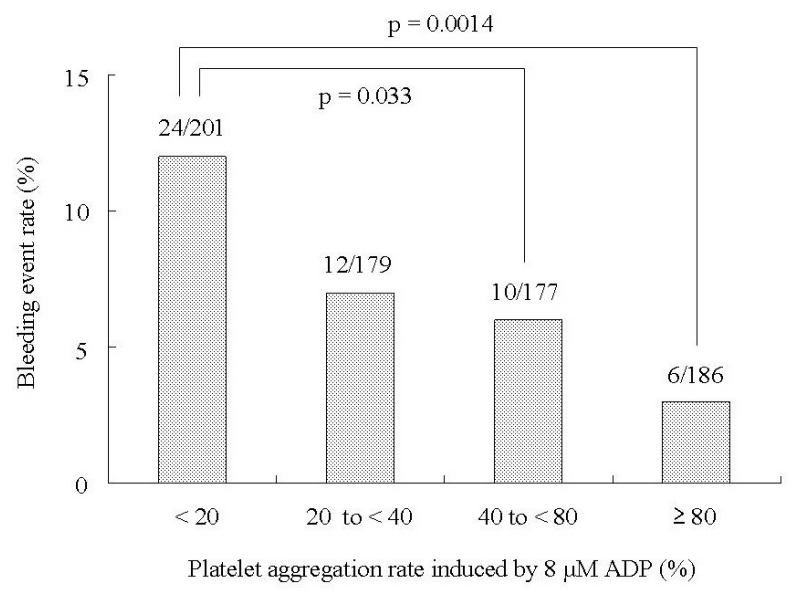

Fig. 1. Bleeding event rate according to quartiles of aggregation rate induced by $8 \mu \mathrm{M} A \mathrm{ADP}$.

events (11.9\% vs. $5.2 \%, p=0.0007$; Fig. 3$)$, and aggregation rates of $\geq 47 \%$ were significantly associated with a greater number of ischemic events $(4.1 \%$ vs. $1.6 \%, p=0.042$; Fig. 4).

\section{Independent Predictors of Bleeding Events}

In univariate Cox proportional hazards analysis, age $>75$ years, eGFR $<60 \mathrm{ml} / \mathrm{min} / 1.73 \mathrm{~m}^{2}$, platelet count $<10 \times 10^{4} / \mu \mathrm{L}$, and an aggregation rate induced

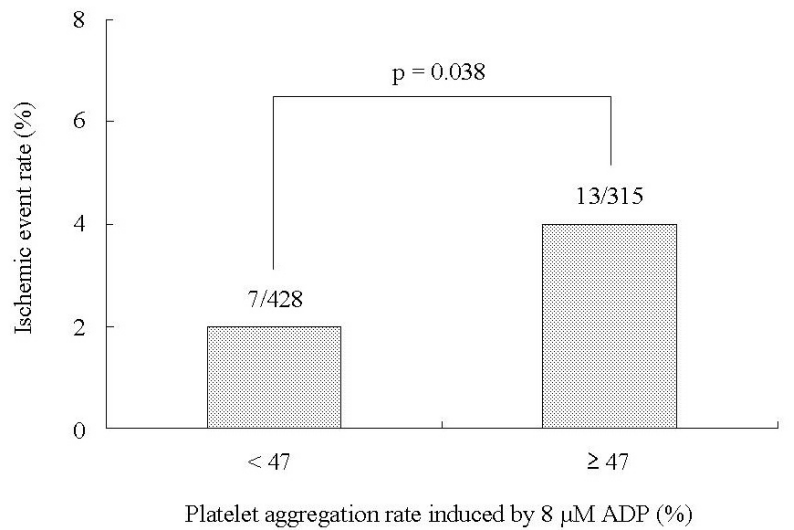

Fig. 2. Ischemic event rate in subjects with a platelet aggregation rate above or below the median aggregation rate induced by $8 \mu \mathrm{M}$ ADP.

by $8 \mu \mathrm{M}$ ADP $<20 \%$ emerged as predictors of bleeding events. In multivariate models including these variables, age $>75$ years (hazard ratio [HR], 1.78; $95 \%$ confidence interval $[\mathrm{CI}], 1.03-3.10 ; p=0.039$ ), eGFR $<60 \mathrm{ml} / \mathrm{min} / 1.73 \mathrm{~m}^{2}$ (HR, $1.82 ; 95 \% \mathrm{CI}$, $1.06-3.18 ; p=0.031$ ), and an aggregation rate induced by $8 \mu \mathrm{M}$ ADP <20\% (HR, 2.18; 95\% CI, $1.24-3.80 ; p=0.0071)$ remained independent predictors of bleeding events (Table 4). 


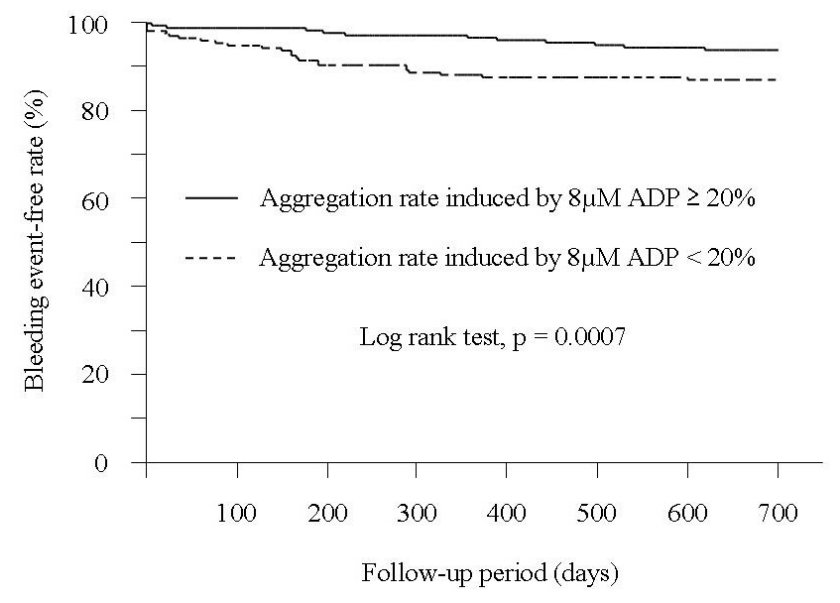

Fig. 3. Kaplan-Meier curves representing patients free of bleeding events.

Study subjects were divided into two groups based on the cut-off value for the aggregation rate induced by $8 \mu \mathrm{M}$ ADP for predicting ischemic events. Continuous line, aggregation rate $\geq 20 \%$; broken line, aggregation rate $<20 \%$.

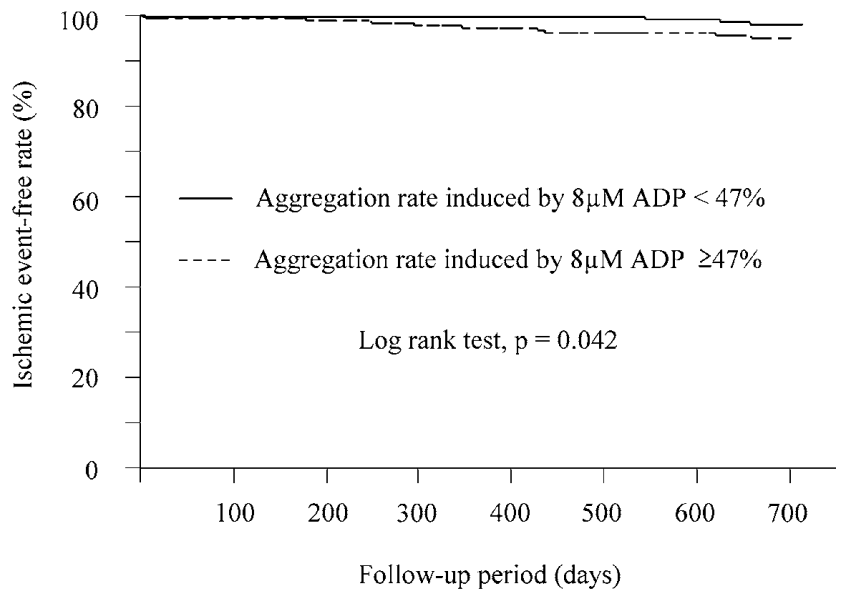

Fig. 4. Kaplan-Meier curves representing patients free of ischemic events.

Study subjects were divided into two groups based on the cut-off value for aggregation rates induced by $8 \mu \mathrm{M}$ of $\mathrm{ADP}$ for predicting ischemic events. Broken line, aggregation rate $\geq 47 \%$; continuous line, aggregation rate $<47 \%$.

Table 4. Cox proportional hazards analysis for determining predictors of bleeding events

\begin{tabular}{|c|c|c|c|c|}
\hline \multirow[b]{2}{*}{ Variables } & \multicolumn{2}{|c|}{ Univariate } & \multicolumn{2}{|c|}{ Multivariate } \\
\hline & $\operatorname{HR}(95 \% \mathrm{CI})$ & $p$ value & $\mathrm{HR}(95 \% \mathrm{CI})$ & $p$ value \\
\hline Age $>75$ years & $1.88(1.09-3.29)$ & 0.023 & $1.78(1.03-3.10)$ & 0.039 \\
\hline Female & $1.01(0.56-1.76)$ & 0.97 & & \\
\hline Body mass index $>25 \mathrm{~kg} / \mathrm{m}^{2}$ & $0.74(0.33-1.53)$ & 0.43 & & \\
\hline Hemoglobin level $<11 \mathrm{~g} / \mathrm{dL}$ & $1.36(0.58-2.84)$ & 0.45 & & \\
\hline Estimated glomerular filtration rate $<60 \mathrm{ml} / \mathrm{min} / 1.73 \mathrm{~m}^{2}$ & $1.99(1.15-3.45)$ & 0.014 & $1.82(1.06-3.18)$ & 0.031 \\
\hline Proton pump inhibitor/H2 blocker & $0.98(0.56-1.69)$ & 0.94 & & \\
\hline Platelet count $<10 \times 10^{4} / \mu \mathrm{L}$ & $2.31(1.01-4.64)$ & 0.048 & $1.84(0.80-3.76)$ & 0.14 \\
\hline Aggregation rate induced by $8 \mu \mathrm{M}$ ADP $<20 \%$ & $2.50(1.44-4.31)$ & 0.0014 & $2.18(1.24-3.80)$ & 0.0071 \\
\hline Dual antiplatelet agents & $1.03(0.55-1.84)$ & 0.92 & & \\
\hline Single antiplatelet agent and warfarin & $1.50(0.75-2.77)$ & 0.24 & & \\
\hline Dual antiplatelet agents and warfarin & $1.62(0.67-3.36)$ & 0.27 & & \\
\hline
\end{tabular}

$\mathrm{HR}$, hazard ratio; CI, confidence interval

\section{Discussion}

To our knowledge, this is the first prospective study of the association between platelet function and the risk of bleeding. Our major finding was that a low platelet aggregation rate demonstrated with a whole blood aggregometer was a significant predictor of bleeding events. We identified bleeding events in $12 \%$ of 201 subjects with aggregation rates of $<20 \%$, which was comparable to the bleeding event rate for an INR of 3.0-4.4 in Italian subjects taking warfa$\operatorname{rin}^{14)}$. Chen and colleagues ${ }^{15)}$ examined the relationship between platelet aggregation and bleeding during coronary bypass grafting and found that patients who had greater clopidogrel-induced platelet inhibition required a significantly higher number of platelet and red blood cell transfusions than patients with lower clopidogrel-induced platelet inhibition. This may support our major result, suggesting the possibility of using a platelet function assay as a tool for the risk stratification of bleeding events. Our finding that excessively suppressed platelet function rather than the number or amount of antiplatelet agents taken was associated with the incidence of bleeding may support the well-known wide interindividual variability in the response to antiplatelet agents, as characterized by 
clopidogrel ${ }^{16-18)}$, suggesting the importance of assessing the in vivo pharmacological effects of these agents. Several investigators reported that increasing the dose or adding antiplatelet agents resulted in stronger platelet inhibition without increasing the number of bleeding complications $s^{8,10,19,20)}$. This seems slightly different from our major finding mentioned above. Possible explanations for the difference are that (1) the subjects included in our study were markedly older than those previous studies; (2) the subjects included in our study were all Japanese (Asian populations have a relatively high incidence of bleeding complications compared with other ethnic groups); (3) in our study, nonfatal bleeding was also considered a primary endpoint; and (4) the platelet function assay was not necessarily the same as those used in previous studies.

In agreement with previous research ${ }^{21-23)}$, an advanced age and decreased eGFR were other independent predictors of bleeding events in our study. GFR is known to decrease with aging, so there would be a close relationship between GFR and age; however, adjustment for age hardly attenuated the association between eGFR and the risk of bleeding. There are reports that decreased GFR may influence platelet function $^{24,25)}$, but this was not shown in our study.

We observed ischemic events more frequently in patients in whom the platelet aggregation rate induced by $8 \mu \mathrm{M}$ ADP was above the mean $(47.3 \%)$ compared with subjects with a rate below the mean. In receiver operating characteristic curve analysis to distinguish patients taking dual antiplatelet agents (aspirin and ticlopidine) from those not taking antiplatelet drugs, the appropriate cut-off value for the aggregation rate induced by $8 \mu \mathrm{M}$ ADP was $47.3 \%(85 \%$ sensitivity and $81 \%$ specificity), which, interestingly, is the same as the mean value for the aggregation rate. Taking these results together, although the positive predictive value of platelet function for the incidence of ischemia is not high, dual antiplatelet therapy may reduce the risk of ischemic events ${ }^{26,27)}$, provided these dual antiplatelet agents act effectively.

Several studies have reported that platelet aggregation function assays were useful for detecting residual platelet reactivity or resistance to antiplatelet agents, which are strongly associated with ischemic events $^{8-10)}$. In our study, we confirmed an additional finding, which is that platelet aggregation function assays are useful for detecting patients at high risk for bleeding events. In particular, whole blood aggregation analysis using a screen filtration pressure method has good reproducibility and easy handling ${ }^{12,13)}$ and requires only a short time. Hence, we presume it would be suitable as a monitoring instrument in an outpatient clinic.

In our study, subjects who took a combination of aspirin and warfarin had a significantly higher number of bleeding events than those who took no medication. Subjects who took other combinations of medications $(n=57)$, including 23 subjects who took various combinations of antiplatelet and anticoagulant agents, also had a relatively high number of bleeding events. These findings are consistent with the results of previous studies, which showed that the concomitant administration of antiplatelet and anticoagulant agents was associated with a relatively high risk of bleeding complications ${ }^{28-30}$. From the results of our study, however, we were unable to conclude that the combined use of antiplatelet and anticoagulant agents was an independent predictor of bleeding events. This may be explained by the fact that the INR values tended to be lower in subjects who took both antiplatelet and anticoagulant agents than in those who took warfarin alone.

The major limitation of our study is that the statistical power was limited because of the relatively small number of bleeding or ischemic events observed. The reason for using $8 \mu \mathrm{M}$ ADP as an aggregation agonist was that among the different concentrations of ADP tried in a preliminary test, this concentration reflected the widest range of platelet functions. However, if other concentrations of ADP or other aggregation agonists, such as collagen or arachidonic acid, had also been used, further insights into this subject may have been obtained. Finally, the extent to which our ex vivo platelet aggregation function tests represent in vivo platelet activity remains unknown. To obtain additional evidence, randomized trials with a large number of subjects are needed to determine whether adjustments to the use of antiplatelet agents, based on findings using a whole blood aggregometer, reduce the risk of bleeding events.

In conclusion, a low platelet aggregation rate determined using a whole blood aggregometer was an independent predictor of bleeding events. Furthermore, a platelet function assay using whole blood aggregometry based on a screen filtration pressure method was useful for identifying patients at high risk for bleeding. Especially in elderly or subjects with decreased renal function, careful monitoring might be necessary in order to prevent overdosing with antiplatelet agents.

\section{Acknowledgments}

We are grateful to the subjects who participated in this study, and to the staff of the clinical laboratory 
of Chugoku Workers Compensation Hospital.

\section{Statement of conflicts of interest}

\author{
The authors have no conflicts of interest.
}

\section{References}

1) Morimoto T, Nakayama M, Saito $Y$, and Ogawa H: Aspirin for primary prevention of atherosclerotic disease in Japan. J Atheroscler Thromb, 2007; 14: 159-166

2) Hart RG, Tonarelli SB, and Pearce LA: Avoiding central nervous system bleeding during antithrombotic therapy: recent data and ideas. Stroke, 2005; 36: 1588-1593

3) Wang TY, Chen AY, Roe MT, Alexander KP, Newby LK, Smith, Jr. SC, Bangalore S, Gibler WB, Ohman EM, and Peterson ED: Comparison of baseline characteristics, treatment patterns, and in-hospital outcomes of Asian versus non-Asian white Americans with non-ST-segment elevation acute coronary syndromes from the CRUSADE quality improvement initiative. Am J Cardiol, 2007; 100: 391-396

4) Mak KH, Bhatt DL, Shao M, Hankey GJ, Easton JD, Fox KA, and Topol EJ: Ethnic variation in adverse cardiovascular outcomes and bleeding complications in the Clopidogrel for High Atherothrombotic Risk and Ischemic Stabilization, Management, and Avoidance (CHARISMA) study. Am Heart J, 2009; 157: 658-665

5) Suzuki S, Yamashita T, Kato T, Fujino T, Sagara K, Sawada H, Aizawa T, and Fu LT: Incidence of major bleeding complication of warfarin therapy in Japanese patients with atrial fibrillation. Circ J, 2007; 71: 761-765

6) Hochholzer W, Trenk D, Bestehorn HP, Fischer B, Valina CM, Ferenc M, Gick M, Caputo A, Büttner HJ, and Neumann FJ: Impact of the degree of peri-interventional platelet inhibition after loading with clopidogrel on early clinical outcome of elective coronary stent placement. J Am Coll Cardiol, 2006; 48: 1742-1750

7) Geisler T, Langer H, Wydymus M, Göhring K, Zürn C, Bigalke B, Stellos K, May AE, and Gawaz M: Low response to clopidogrel is associated with cardiovascular outcome after coronary stent implantation. Eur Heart J, 2006; 27: 2420-2425

8) Bliden KP, DiChiara J, Tantry US, Bassi AK, Chaganti SK, and Gurbel PA: Increased risk in patients with high platelet aggregation receiving chronic clopidogrel therapy undergoing percutaneous coronary intervention: is the current antiplatelet therapy adequate? J Am Coll Cardiol, 2007; 49: 657-666

9) Marcucci R, Gori AM, Paniccia R, Giusti B, Valente $S$, Giglioli C, Buonamici P, Antoniucci D, Abbate R, and Gensini GF: Cardiovascular death and nonfatal myocardial infarction in acute coronary syndrome patients receiving coronary stenting are predicted by residual platelet reactivity to ADP detected by a point-of-care assay: a 12-month follow up. Circulation, 2009; 119: 237-242

10) Bonello L, Camoin-Jau L, Arques S, Boyer C, Panagides D, Wittenberg O, Simeoni MC, Barragan P, DignatGeorge F, and Paganelli F: Adjusted clopidogrel loading doses according to vasodilator-stimulated phosphoprotein phosphorylation index decrease rate of major adverse cardiovascular events in patients with clopidogrel resistance: a multicenter randomized prospective study. J Am Coll Cardiol, 2008; 51: 1404-1411

11) Levey AS, Bosch JP, Lewis JB, Greene T, Rogers N, and Roth D: A more accurate method to estimate glomerular filtration rate from serum creatinine: a new prediction equation. Modification of Diet in Renal Disease Study Group. Ann Intern Med, 1999; 130: 461-470

12) Ozeki Y, Sudo T, Toga K, Nagamura $Y$, Ito H, Ogawa T, and Kimura Y: Characterization of whole blood aggregation with a new type of aggregometer by a screen filtration pressure method. Thromb Res, 2001; 101: 65-72

13) Sudo T, Ito H, Ozeki Y, and Kimura Y: Estimation of anti-platelet drugs on human platelet aggregation with a novel whole blood aggregometer by a screen filtration pressure method. Br J Pharmacol, 2001; 133: 1396-1404

14) Palareti G, Leali N, Coccheri S, Poggi M, Manotti C, D' Angelo A, Pengo V, Erba N, Moia M, Ciavarella N, Devoto G, Berrettini M, and Musolesi S: Bleeding complications of oral anticoagulant treatment: an inception-cohort, prospective collaborative study (ISCOAT). Italian Study on Complications of Oral Anticoagulant Therapy. Lancet, 1996; 348: 423-428

15) Chen L, Bracey AW, Radovancevic R, Cooper JR Jr, Collard CD, Vaughn WK, and Nussmeier NA. Clopidogrel and bleeding in patients undergoing elective coronary artery bypass grafting. J Thorac Cardiovasc Surg, 2004; 128: 425-431

16) Mega JL, Close SL, Wiviott SD, Shen L, Hockett RD, Brandt JT, Walker JR, Antman EM, Macias W, Braunwald E, and Sabatine MS: Cytochrome P-450 polymorphisms and response to clopidogrel. N Engl J Med, 2009; 360: 354-362

17) Hochholzer W, Trenk D, Frundi D, Blanke P, Fischer B, Andris K, Bestehorn HP, Büttner HJ, and Neumann FJ. Time dependence of platelet inhibition after a 600-mg loading dose of clopidogrel in a large, unselected cohort of candidates for percutaneous coronary intervention. Circulation, 2005; 111: 2560-2564

18) Serebruany VL, Steinhubl SR, Berger PB, Malinin AI, Bhatt DL, and Topol EJ: Variability in platelet responsiveness to clopidogrel among 544 individuals. J Am Coll Cardiol, 2005; 45: 246-251

19) Abuzahra M, Pillai M, Caldera A, Hartley WB, Gonzalez R, Bobek J, Dokainish H, and Lakkis N: Comparison of higher clopidogrel loading and maintenance dose to standard dose on platelet function and outcomes after percutaneous coronary intervention using drug-eluting stents. Am J Cardiol, 2008; 102: 401-403

20) Goto S, Yamaguchi T, Ikeda $Y$, Kato K, Yamaguchi H, and Jensen P: Safety and exploratory efficacy of the novel thrombin receptor (PAR-1) antagonist SCH530348 for non-ST-segment elevation acute coronary syndrome. J Atheroscler Thromb, 2010; 17: 156-164

21) Nikolsky E, Mehran R, Dangas G, Fahy M, Na Y, Pocock SJ, Lincoff AM, and Stone GW: Development and validation of a prognostic risk score for major bleeding in patients undergoing percutaneous coronary intervention via 
the femoral approach. Eur Heart J, 2007; 28: 1936-1945

22) Manoukian SV: Predictors and impact of bleeding complications in percutaneous coronary intervention, acute coronary syndromes, and ST-segment elevation myocardial infarction. Am J Cardiol, 2009; 104: 9C-15C

23) Bertrand OF, Larose E, Rodés-Cabau J, Gleeton O, Taillon I, Roy L, Poirier P, Costerousse O, and Larochellière $\mathrm{RD}$ : Incidence, predictors, and clinical impact of bleeding after transradial coronary stenting and maximal antiplatelet therapy. Am Heart J, 2009; 157: 164-169

24) Noris $M$ and Remuzzi G: Uremic bleeding: closing the circle after 30 years of controversies? Blood, 1999; 94: 2569-2574

25) Bos MJ, Koudstaal PJ, Hofman A, and Breteler MM: Decreased glomerular filtration rate is a risk factor for hemorrhagic but not for ischemic stroke: the Rotterdam Study. Stroke, 2007; 38: 3127-3132

26) Bhatt DL, Fox KA, Hacke W, Berger PB, Black HR, Boden WE, Cacoub P, Cohen EA, Creager MA, Easton JD, Flather MD, Haffner SM, Hamm CW, Hankey GJ, Johnston SC, Mak KH, Mas JL, Montalescot G, Pearson TA, Steg PG, Steinhubl SR, Weber MA, Brennan DM, FabryRibaudo L, Booth J, and Topol EJ: CHARISMA Investigators: Clopidogrel and aspirin versus aspirin alone for the prevention of atherothrombotic events. N Engl J Med, 2006; 354: 1706-1717

27) Steinhubl SR, Berger PB, Mann JT 3rd, Fry ET, DeLago
A, Wilmer C, and Topol EJ: CREDO Investigators: Clopidogrel for the Reduction of Events During Observation. Early and sustained dual antiplatelet therapy following percutaneous coronary intervention: a randomized controlled trial. JAMA, 2002; 288: 2411-2420

28) Toyoda K, Yasaka M, Iwade K, Nagata K, Koretsune Y, Sakamoto T, Uchiyama S, Gotoh J, Nagao T, Yamamoto M, Takahashi JC, and Minematsu K: Bleeding with Antithrombotic Therapy (BAT) Study Group. Dual antithrombotic therapy increases severe bleeding events in patients with stroke and cardiovascular disease: a prospective, multicenter, observational study. Stroke, 2008; 39: 1740-1745

29) Flaker GC, Gruber M, Connolly SJ, Goldman S, Chaparro S, Vahanian A, Halinen MO, Horrow J, and Halperin JL: SPORTIF Investigators: Risks and benefits of combining aspirin with anticoagulant therapy in patients with atrial fibrillation: an exploratory analysis of stroke prevention using an oral thrombin inhibitor in atrial fibrillation (SPORTIF) trials. Am Heart J, 2006; 152: 967-973

30) Warfarin Antiplatelet Vascular Evaluation Trial Investigators, Anand S, Yusuf S, Xie C, Pogue J, Eikelboom J, Budaj A, Sussex B, Liu L, Guzman R, Cina C, Crowell R, Keltai M and Gosselin G: Oral anticoagulant and antiplatelet therapy and peripheral arterial disease. $\mathrm{N}$ Engl J Med, 2007; 357: 217-227 